\title{
ALIANÇAS ESTRATÉGICAS PARA O DESENVOLVIMENTO SUSTENTÁVEL
}

\section{Strategic alliance to sustainable development}

\author{
Waleska Silveira Lira
}

Doutora em Engenharia de Produção. Professora Titular da Universidade Estadual da Paraíba waleska.silveira@oi.com.br Geuda Anazile da Costa Gonçalves Doutoranda em Recursos Naturais - UFCG. Professora da Universidade Estadual da Paraíba geuda@uol.com.br Gesinaldo Ataíde Cândido Doutor em Engenharia de Produção -UFSC. Professor Titular da Universidade Federal de Campina Grande gacandido@uol.com.br

Artigo recebido para publicação em 25/03/2007 e aceito para publicação em 07/08/2007

RESUMO: $\quad$ O artigo trata de avaliar o impacto da implementação da Estratégia de Desenvolvimento Regional Sustentável - DRS proposta pelo Banco do Brasil na Cooperativa das Bordadeiras de Alagoa Nova - COOBAN. Assim, foi realizado um levantamento bibliográfico, complementado de uma coleta de dados junto aos agentes envolvidos no processo e que fazem parte da cooperativa. Como resultado, pode-se identificar que os impactos da aliança estratégica proporcionada pela DRS do Banco do Brasil, enquanto articuladora, junto à Cooperativa das Bordadeiras de Alagoa Nova são positivos, apresentando problemas em aspectos isolados, que poderão ser superados com ações corretivas por parte das Instituições inseridas no processo. Sugere-se, no entanto, a adoção e implementação de medidas estratégicas como curso de administração financeira e gestão de negócio, oferecidos pelo SEBRAE; contínuo apoio do Governo do Estado e Prefeitura tanto no que diz respeito à ampliação da participação das artesãs em Feiras de Artesanato como também no monitoramento da gestão da cooperativa para que a mesma torne-se, verdadeiramente, auto-sustentável o que impulsiona o desenvolvimento Regional Sustentável, legitimando o papel de articulador do Banco do Brasil.

Palavras-chave: Desenvolvimento, Sustentável, Estratégia.

ABSTRACT: This paper deal with the evaluation of the impact of the implementation of the Regional Sustainable Development Strategy (RSD) proposed by Banco do Brasil in the Cooperativa das Bordadeiras de Alagoa Nova, СООВAN. In this way, it was done a literature review, in addition to a data obtained from the agents involved in the process and that make part of the cooperative. As a result it can be identify that the impacts of the strategy alliance give by RSD from Banco do Brasil, as an articulator, in the COOBAN are positives, presenting isolated problems that can be overcome with corrective actions from the institution involved in the process. It was suggested; however, the adoption and implementation of strategic decisions as a course of financial management and business, offered by SEBRAE, continue support from State 
Government and Prefecture in relation to the extend the participation of the craft makers in fairs or conventions, also in the inspection of the cooperative management to become, truly, auto-sustainable and a drive force to the regional sustainable development, by validating the role of the Banco do Brasil as articulator.

Keywords: Development; Sustainable; Strategy

\section{INTRODUÇÃO}

Apesar da recorrente alusão à globalização na quase totalidade dos discursos e análises econômicas, a maioria da produção nacional no Brasil não tem como destino final os mercados internacionais. Segundo dados do Banco Mundial, no ano 2000 as exportações de bens e serviços representavam somente $10,9 \%$ do Produto Interno Bruto do Brasil. Falando de outra forma, mais de $89 \%$ da produção brasileira se realiza no mercado interno. Em nível mundial este percentual é de 23,2\%, o que significa que a maioria da produção no mundo tem lugar, também, nos mercados locais. Isso sem contar a produção que não é objeto de transações formais, aquela que se realiza para atender ao consumo próprio familiar e outras atividades produtivas que não se incluem no Sistema de Contas Nacionais.

Outro aspecto deve ser considerado com o processo de globalização: o aprofundamento das desigualdades Norte-Sul, o aumento do desemprego - mesmo nos países ditos desenvolvidos - e a fome, agravada pelas guerras tribais e religiosas nas regiões mais miseráveis do Planeta. O mundo vive uma situação crítica, em tempos de Internet e globalização, temos hoje no mundo cerca de 1,4 bilhões de pessoas com renda menor que U\$ 1,00 dia.

Neste sentido, pode-se questionar qual o modelo mais correto de desenvolvimento, ou seja, qual o futuro que se pretende alcançar. Um futuro mais justo cujas questões econômicas se encontram com as questões sociais e as do meio ambiente, considerando que o verdadeiro objetivo do desenvolvimento é melhorar a qualidade de vida humana. Deve ser um processo que permita aos seres humanos desenvolverem plenamente seus potenciais e levar vidas dignas e satisfatórias.

Apesar de haver divergências de opiniões sobre os objetivos do desenvolvimento, alguns deles são praticamente universais. Como, por exemplo, uma vida longa e saudável; educação; acesso aos recursos necessários para um padrão de vida decente; liberdade política; garantia dos direitos humanos e proteção contra a violência.

Até recentemente, as distorções sociais vinham sendo tratadas nos discursos políticos como matéria de segunda ordem, que deveriam ser resolvidas apenas a posteriori das questões econômicas. Sob este ângulo, o desenvolvimento era encarado como uma questão econômica, dissociada das outras dimensões. A partir das preocupações expostas no relatório Brundtland em 19877 , a noção de desenvolvimento sustentável vem sendo exaustivamente discutida, o que permitiu uma visão e um entendimento mais consciente dos problemas ambientais, não apenas por parte dos cientistas e dos cidadãos mais esclarecidos, mas dos gestores políticos. Hoje, a noção de sustentabilidade do desenvolvimento permite perceber, de forma integrada, as diferentes dimensões ambientais da sociedade - ecológica, social, cultural, econômica, política e institucional.

Esta percepção dos diferentes aspectos e atores da sociedade alicerça a totalidade do entendimento da necessidade da criação de mecanismos eficazes para se associar crescimento econômico, inclusão social e respeito ao meio ambiente.

Desenvolver-se com sustentabilidade é um desafio que demanda a elaboração de ações voltadas 
para o atendimento de necessidades essenciais à humanidade, respeitando-se as limitações do ambiente, preocupando-se com as gerações futuras e considerando igualmente os aspectos socioculturais, econômicos e políticos.

Algumas ações estão sendo implementadas em nível de governo, voltadas para um desenvolvimento econômico sustentável, que seja capaz de gerar riquezas e melhoria da qualidade de vida enquanto promove o equilíbrio social e impede a degradação ambiental.

O Banco do Brasil em parceira com o governo federal tem enfatizado o apoio à implantação de programas de Desenvolvimento Regional Sustentável - DRS, como forma de catalisar as ações dos diferentes agentes existentes nas comunidades, no sentido de superar as dificuldades e carências e promover o desenvolvimento não apenas de uma, mas de todas as etapas de uma atividade produtiva.

Essa medida visa implantar uma nova maneira de atuar junto a comunidades localizadas em regiões carentes, buscando mobilizar os agentes econômicos, políticos e sociais para impulsionar o desenvolvimento sustentável. Com isso, pretende também promover a geração de trabalho e renda de forma sustentável, inclusiva e participativa, considerando as características locais, de natureza econômica, social, ambiental, institucional, política e cultural.

O trabalho iniciou-se nas regiões Norte e Nordeste, nos Vales do Jequitinhonha (Minas Gerais), Mucuri (Minas Gerais, Bahia e Espírito Santo) e Ribeira (São Paulo) e na Bacia do Rio Itabapoana (Espírito Santo, Minas Gerais e Rio de Janeiro), áreas priorizadas em função dos baixos Índices de Desenvolvimento Humano (IDH).

É nesse contexto que se insere a Cooperativa das Bordadeiras de Alagoa Nova COOBAN, instituição sem fins lucrativos, fundada em maio de 2004. O programa DRS-BB, após pesquisa para identificação de vocação ou mesmo demandas ainda não atendidas naquele município, escolheu a
COOBAN e inseriu a mesma em seu programa de Desenvolvimento Regional Sustentável, o que se justificou pela necessidade de tornar o negócio mais competitivo devido aos novos condicionantes do mercado e à necessidade de modernização que, segundo Farina, citado por Jank \& Galan (1999), gera problemas como: concorrência desleal; comportamento oportunista, entre outros.

Em virtude desse novo quadro que se apresenta, vários atores da cadeia produtiva passaram a encontrar dificuldades de-se adaptar a essa nova realidade. No caso das cooperativas, essas foram umas das que mais sofreram com a inserção do novo ambiente competitivo, devido, principalmente, as suas origens e ao crescimento irregular atrelado à baixa capacidade de se adaptarem de forma eficiente às variáveis do macroambiente. Por conseguinte, encontram dificuldades em atender requisitos mínimos de competitividade como: qualidade e produtividade, capacitação tecnológica e de organização (NICÁCIO, 1997).

A partir dessas constatações, o estudo tem como objetivo discutir o modelo de desenvolvimento econômico sustentável em nível regional, relacionando os aspectos relativos a estratégias de Desenvolvimento Regional Sustentável propostas pela Banco do Brasil e avaliando o impacto da gestão estratégica no desenvolvimento sustentável, a partir da implementação da estratégia DRS na COOBAN Cooperativa das Bordadeiras de Alagoa Nova.

Tal fato torna-se relevante visto que as cooperativas ocupam posição de destaque naquela região. Para efeito do processo investigativo foi realizada uma pesquisa bibliográfica que possibilitou levantar dados e construir um arcabouço teórico que serviu de base para a análise dos resultados apresentados. A pesquisa pode ser considerada um estudo de caso já que verificou a importância das estratégias de Desenvolvimento Regional Sustentável no caso da Cooperativa das Bordadeiras de Alagoa Nova-COOBAN. 
Alianças estratégicas para o desenvolvimento sustentável

Waleska Silveira Lira, Geuda Anazile da Costa Gonçalves, Gesinaldo Ataíde Cândido

\section{DESENVOLVIMENTO SUSTENTÁVEL}

O século XX testemunhou uma exploração dos recursos naturais mundiais sem precedentes, cuja prioridade era alimentar a atividade econômica, o que refletiu uma deterioração física dos grandes componentes da biosfera - a atmosfera, os oceanos, a cobertura dos solos, o sistema climático e as espécies animais e vegetais. As pressões sobre o meio ambiente do planeta foram ampliadas a partir da expansão econômica que sucedeu o pós-guerra.

O processo de industrialização das economias desenvolvidas foi responsável por uma grande transformação social, política e cultural, além da melhoria qualitativa das condições de vida da população de certos países, a industrialização tem estado associada ao processo de desenvolvimento.

A Revolução Industrial é considerada a base do processo de desenvolvimento (Sunkel, 1980: 3). A partir da década de 1960, a caracterização de um processo de desenvolvimento econômico, significava a existência de um crescimento econômico, medido principalmente por meio dos indicadores de natureza econômica.

Na década de 80, cresce a preocupação com os impactos econômico/social/ambiental (Veiga, 1997: 101), decorrentes do aumento da poluição nas economias industrializadas, o possível esgotamento de certos recursos naturais básicos, como dos com-bustíveis fósseis, e do surgimento de desequilíbrios ambientais globais (Foladori, 1999:1; Mueller, 2000: 46).

A evolução do processo de desenvolvimento e o seu impacto sobre o meio ambiente ocorreram lentamente e puderam ser notados, a princípio, quando os problemas ambientais se situavam apenas em nível local. Em seguida, a degradação ambiental passou a ser considerada um problema dos estados e, finalmente, a preocupação com a natureza atingiu níveis globais (Barbieri, 1997: 15).

O modelo de desenvolvimento adotado após a segunda guerra mundial (1945) revelou rapidamente sua insustentabilidade por ser um agente de quebra do equilíbrio ecológico (Nosso Futuro Comum, 1988). Nas últimas décadas, ocorreu um grande crescimento urbano junto às atividades de produção e consumo, verificando-se conseqüentemente um grande aumento na emissão de resíduos na atmosfera, nas águas superficiais e subterrâneas e no solo. No entanto, todos os problemas ambientais estavam ligados ao estilo de desenvolvimento praticado pelos países (Barbieri, 1997: 15; Mueller, 2000: 5). Diante disso, se destacam, como os principais elementos causadores da degradação ambiental, a escala da economia e a magnitude da população dos países (Mueller, 2000: 3). Ou seja, quanto maior a produção e o consumo, e quanto maior o crescimento demográfico, maior o impacto sobre a natureza (Mueller, 2000: 3).

Uma nova visão de mundo que relaciona a atividade econômica com justiça social e a proteção ambiental está mudando a conduta das empresas e da sociedade. As instituições governamentais e nãogovernamentais, a mídia, a sociedade civil e as instituições financeiras têm, então, exposto os problemas ambientais da atividade produtiva e forçado as organizações a adotarem sistemas de gestão e controle da variável ambiental. Os investimentos na área ambiental foram, freqüentemente, considerados como necessários, entretanto, hoje devem ser vistos como estratégicos a atuação das empresas, gerando benefícios sociais, ecológicos e econômicos.

Este cenário em que a sociedade de um modo geral está inserida exige uma profunda reestruturação na sua conduta para resolver os problemas ambientais.

A busca do crescimento econômico protegendo o meio ambiente, visando assegurar a sobrevivência das gerações futuras, na prática, tem sido um objetivo extremamente difícil de ser alcançado. Essa deve ser a busca constante, podendo ser atingida por meio das propostas do desenvolvimento sustentável, cuja definição, mais abrangente, explicita conceitos de ecoeficiência e ecodesenvolvimento (ACIESP, 1987): 
modelo de desenvolvimento que leva em consideração, além de fatores econômicos, aqueles de caráter social e ecológico, assim como as disponibilidades dos recursos vivos e inanimados e as vantagens $e$ os inconvenientes, a curto e em longo prazos, de outros tipos de ação.

Diante da complexidade econômica e ecológica atuais, pois tanto as considerações sócioeconômicas como as ecológicas por parte da sociedade, empresas e governos, são individualizadas. Dessa forma, torna-se difícil chegar a um objetivo consensual, considerando que os fatores e os objetivos sociais, legais, religiosos e demográficos são muita vezes divergentes, e que também interferem na aplicação de considerações e diretrizes ecológicas às finalidades e processos de desenvolvimento (RESENDE et al., 1996). Apesar das divergências, já existe um número considerável de experiências cientificas que apresentam resultados satisfatórios em desenvolvimento tecnológico, econômico e comercial sustentável. Emerge nos mais diversos setores, tais como: no transporte, na construção civil, na indústria, nas explorações florestais, na agropecuária e na mineração. Porém, em um ritmo ainda abaixo do desejável e necessário.

O reconhecimento da intensidade da crise ambiental começou a gestar uma nova mentalidade em que a biosfera passou a ser percebida como espaço comum para todos os seus habitantes. O movimento de conscientização mundial a respeito da questão ambiental iniciou-se nos anos 60 , intensificando-se a partir da Conferência das Nações Unidas sobre o Meio Ambiente Humano (Estocolmo, 1972). Paralelamente, nas três últimas décadas, aprofundou-se consideravelmente o conhecimento científico acerca dos problemas ambientais, bem como expandiu-se a percepção dos impactos sócio-econômicos causados por esses problemas e mesmo da possibilidade de ameaça à perpetuação da vida no planeta, colocando em discussão a necessidade de uma nova racionalidade no processo de desenvolvimento, baseada em novos modos de exploração dos recursos naturais, de novos critérios de investimento e de um outro padrão técnico-científico.

O parâmetro central deveria ser o atendimento das necessidades das gerações presentes, sem comprometer as das gerações futuras. A questão ambiental passou a ser um fator importantíssimo na disputa entre os interesses e pontos de vista dos países do Norte e do Sul, no que diz respeito à atribuição de responsabilidades pela degradação do meio ambiente global e também pelo ônus de sua proteção, impondo assim, novas condicionantes sobre o fluxo e a distribuição de riqueza, poder e informações entre países, bem como introduzem-se novos temas nas relações política e econômica internacionais, tais como a preservação e o aproveitamento dos nichos de biodiversidade existentes no planeta, os limites à utilização dos recursos naturais disponíveis em cada país e o livre acesso a tecnologias mais limpas.

Um fator, ainda considerado grave, referese ao domínio de informações sobre as condições ambientais e sobre os recursos naturais das diferentes partes do planeta como também, o acesso aos novos conhecimentos científicos e tecnológicos necessários à proteção do meio ambiente e ao seu aproveitamento econômico e social.

A sociedade desconhece o número certo de espécies existentes no planeta, sua distribuição geográfica, suas características biológicas e sua vulnerabilidade às mudanças ambientais; nem se detêm informações precisas sobre as atuais taxas de redução da biodiversidade.

Nos países do Sul, dos cerca de 1,4 milhão de espécies em todo o mundo já catalogadas pela literatura científica, apenas 500 mil são de regiões tropicais e subtropicais. Esses dados revelam conhecimento restrito sobre tais regiões, comparativamente ao conhecimento já gerado sobre as regiões do Norte, considerando que entre $50 \%$ e dois terços das espécies hoje existentes vivem nos trópicos, das quais, por sua vez, cerca de dois terços seriam exclusivos das florestas tropicais úmidas.

Diante desse quadro, a ampliação da infor- 
mação a respeito das taxas atuais e futuras de extinção de espécies e das implicações econômicas e sociais desse processo, bem como a difusão dessas informações para o público em geral têm sido apontadas como elementos básicos em uma estratégia imediata para se evitar a rápida perda de biodiversidade no mundo .

De acordo com a abordagem feita pela ICLEI International Council for Local Environmental Initiatives (1996), a sustentabilidade envolve três esferas de desenvolvimento: (i) econômico; (ii) social; e, (iii) meio-ambiental.

Um aspecto importante é o entendimento e a conscientização de que o desenvolvimento precisa ser visto dentro de um contexto sistêmico. Essa é uma visão amplamente adotada por vários estudiosos (FENZL, 1998; BARBIERI, 2000; FREY, 2003; CAPRA, 2003; GODET, 2004; GÜELL, 2004).

Casarotto Filho e Pires (2001) mostram que as estratégias de desenvolvimento sustentável apresentam características que podem ser vistas através de uma compreensão conjunta das dimensões econômica, social, política e ambiental, fator essencial para iniciar um processo que garanta sustentabilidade.

Diz ainda que a visão e capacidade de análise e identificação das prioridades imediatas e futuras devem ser consideradas como estratégias de desenvolvimento, dando-se prioridade à participação social neste processo.

A influência do mercado nos negócios humanos sem dúvida é muito maior do que a de qualquer partido político ou código de ética. Segundo o Institute for Policy Studies, em Washington, o poder econômico das maiores corporações do mundo se tornou maior do que o dos países onde elas operam. Na verdade, mais da metade das 100 maiores economias do mundo são corporações, não países. E as 200 maiores economias, que controlam $28 \%$ da economia mundial, empregam menos de $1 / 3$ dos trabalhadores do mundo.
As novas concepções de desenvolvimento, de âmbito local e sustentável, que permeiam o cenário global influenciam as transformações nos cenários locais, criam possibilidades para que a efetivação de políticas públicas assumam características específicas em cada local onde são aplicadas, devido, principalmente, à trajetória política, econômica e social assumida por cada sociedade local.

Por isso, por mais que essas políticas sejam de caráter generalizante sua efetivação perpassará por determinações que emergem no cenário local, sendo que essa diferenciação pode ter como uma de suas explicações a complexidade das redes institucionais.

A proposta de desenvolvimento com base sustentável requer uma nova concepção da interação existente entre o homem e o meio no qual está inserido, como uma forma de relacionar desenvolvimento social, econômico e sustentabilidade ambiental. A partir deste contexto, caberá às instituições públicas, em tese, construírem conjuntamente para guiarem diretrizes que serão seguidas para o desenvolvimento regional.

\section{DESENVOLVIMENTO REGIONAL SUSTENTÁVEL-ESTRATÉGIA DO BANCO DO BRASIL}

O Desenvolvimento Regional Sustentável tem como objetivo implementar uma nova forma de atuar junto às comunidades, em que se busca mobilizar os agentes econômicos, políticos e sociais para impulsionar o desenvolvimento sustentável das regiões carentes do Brasil. Pretende-se, com isso, promover geração de trabalho e renda de forma sustentável, inclusiva, participativa, considerando-se, nesse processo as características locais, de natureza econômica, social, ambiental, institucional, política e cultural. Para o Banco do Brasil (2006, p. LIC 141.1.1.1.1) Desenvolvimento Sustentável é:

Aquele que leva à construção de comunidades humanas que buscam atingir um padrão de organização em rede, com caracte- 
Alianças estratégicas para o desenvolvimento sustentável Waleska Silveira Lira, Geuda Anazile da Costa Gonçalves, Gesinaldo Ataíde Cândido

rísticas de interdependência, reciclagem, parceria, flexibilidade e diversidade, considerando-se que as ações sejam economicamente viáveis, socialmente justas, ambientalmente corretas e culturalmente diversificadas.

Assim sendo, o princípio básico da Estratégia DRS está calcado no tripé: economicamente viável, socialmente justo e ambientalmente correto, ancorado na diversidade cultural. A diversidade cultural passa por todas as dimensões da sustentabilidade: social, ambiental e econômica. Sendo assim:

O DRS é uma estratégia do Banco do Brasil e se baseia em um modelo de negócio que tem por objetivos: gerar trabalho e renda de forma sustentável; promover o acesso ao crédito (bancarização); estimular e aperfeiçoar a capacidade de organização social (associativismo e cooperativismo); desenvolver atividades produtivas, agregando valor aos produtos e serviços; promover a inclusão social e a inserção das pessoas nos mercados de trabalho, da produção e de consumo; e disseminar a cultura empreendedora (BANCO DO BRASIL, 2006, p. LIC 141.1.1.1.3).

Em virtude do ambiente empresarial altamente competitivo dos dias atuais, as empresas têm buscado exaustivamente flexibilidade e inovação para tornarem-se sustentáveis. As parcerias e alianças são estratégias que geram vantagem competitiva. Bons parceiros suprem deficiências e se complementam em conhecimento técnico, desenvolvimento de competências e habilidades que proporcionam uma melhor performance empresarial. Keegan e Green (1999, p. 42) apontam três características das alianças estratégicas:

1. Os participantes continuam independentes após a formação da aliança;

2. Os participantes compartilham os benefícios da aliança e o controle sobre o desempenho das tarefas a eles atribuídas;
3. Os participantes contribuem constantemente na área de tecnologia, produtos e outras áreas-chaves estratégicas.

Por meio de parcerias e de alianças estratégicas, as organizações podem desenvolver novas atividades, iniciar novos projetos, abrir frentes de atuação, fortalecer projetos em andamento, ampliar o leque de conhecimentos, captar recursos, alcançálos melhor sem prejuízo do trabalho e aumentar a capacidade de intervenção, podendo, ainda, superar suas lacunas e preencher espaços importantes onde não são tão fortes. Yoshino e Rangan (1996, p. 20) entendem que:

Uma aliança estratégica vincula facetas específicas das atividades-fins de duas ou mais empresas. No fundo, o elo é uma parceria comercial que aumenta a eficácia das estratégias competitivas das organizações participantes, propiciando o intercâmbio mútuo e benéfico de tecnologias, qualificações ou produtos.

Portanto, aliança estratégica é aquela em que a associação está voltada para a conquista de melhores posições e objetivos. Para conseguir isso, é necessário somar esforços a fim de atingir novos desafios, alcançar os objetivos almejados.

O principal fator de sucesso da Estratégia DRS é o princípio participativo, construtivista de sua metodologia que se baseia no processo de Alianças Estratégicas ou "concertação".

A 'concertação', com o sentido de orquestração, é uma ação conjunta que aglutina parceiros da esfera federal, estadual, municipal, sociedade civil, políticos, empresários, entidades religiosas e ONGs, dentre outros, em prol de um objetivo comum e maior que é o desenvolvimento sustentável. (BANCO DO BRASIL, 2006, p. LIC 141.1.4.1.4).

A implantação das ações de Desenvolvimento Regional Sustentável do Banco do Brasil visa fortalecer o associativismo, a agricultura familiar, os 
mini e pequenos empresários formais ou informais, as cooperativas populares, em suma, o desenvolvimento de atividades produtivas identificadas como vocação das mais diferentes regiões, com respeito à cultura local, os níveis de organização. As atividades produtivas do Desenvolvimento Regional Sustentável são identificadas buscando-se estabelecer um diálogo entre o local e o global, fortalecendo-se os laços culturais e as tradições e potencialidades locais.

O sucesso da Estratégia DRS vai gerar novas oportunidades de negócio para os parceiros, promover maior participação no mercado de baixa renda, ampliação da base de clientes e contribuir para a fidelização de clientes.

As ações do DRS - Desenvolvimento Regional Sustentável do Banco do Brasil se iniciam com a mobilização e treinamento dos funcionários envolvidos. E compreende as seguintes fases:

a) Sensibilização, Mobilização e Instrumentalização;

b) Escolha da Atividade Produtiva;

c) Formação da Equipe de Trabalho DRS;

d) Elaboração do Diagnóstico e do Plano de Negócios DRS;

e) Análise;

f) Implementação - Plano de Negócios DRS;

g) Monitoramento e Avaliação.

As ações de Desenvolvimento Regional Sustentável - DRS - do Banco do Brasil na Paraíba envolvem 91 agências, cujos funcionários estão capacitados a atuar de acordo com as premissas dessa Estratégia Negocial.Segundo dados do Banco do Brasil (2006), existem 77 Planos de Negócios DRS em execução, com 4.917 famílias envolvidas. Além desses, outros 34 Planos de Negócios DRS estão em elaboração, cujas atividades produtivas na Paraíba envolvem a apicultura, a bovinocultura de leite e a criação de tilápia.

\section{ASPECTOS METODOLÓGICO DA PESQUISA}

A pesquisa abordou as bordadeiras da COOBAN com o intuito de analisar o impacto causado pela a implantação da Estratégia DRS do Banco do Brasil no que diz respeito ao desenvolvimento sustentável.

O método utilizado foi o descritivo que de acordo com Rudio (2003, p. 71): “está interessado em descobrir e observar fenômenos, procurando descrevê-los classificá-los e interpretá-los”. E de estudo de caso que segundo Triviños (1990, p. 110-111): "Estes estudos têm por objetivos aprofundarem a descrição de determinada realidade". O referente autor ainda afirma: "No estudo de caso, os resultados são válidos só para o caso que se estuda”.

Para a realização da presente pesquisa utilizou-se universo de vinte e sete bordadeiras pertencentes à cooperativa. As variáveis estudadas foram: Renda; Promoção/ Divulgação; Acesso ao Crédito; Auto Estima e Sustentabilidade.O instrumento de pesquisa utilizado foi o questionário contendo dez questões afirmativas, e utilizando a escala de Likert. Esta escala atribui pontos a diferentes categorias de respostas, criando um limite que varia de 1 a 5 , sendo 1 o peso de maior discordância e 5 o peso de maior concordância, correspondendo, respectivamente, a discordo totalmente e concordo totalmente.

\section{OBJETO DE ESTUDO}

A Cooperativa das Bordadeiras de Alagoa Nova (COOBAN) foi fundada em maio de 2004 e surgiu da necessidade de organizar um grupo já existente na comunidade, que já desenvolvia um trabalho de alta qualidade, passado de geração em geração, e que formava no Centro de Artesanato Raimundo Asfora novas turmas de artesãs a cada ano. 
Em junho de 2001, técnicos do Artesanato Solidário/ Central Artesol, uma organização da sociedade civil sem fins lucrativos e técnicos do SEBRAE/ PB fizeram a primeira visita a Alagoa Nova. Com a mobilização do grupo e depois de estabelecidos convênios com o SEBRAE/PB, a UFPB e a prefeitura local, o Artesanato Solidário/Central Artesol iniciou o projeto "Bordados de Alagoa Nova” em fevereiro de 2002.

Em 2005, o Banco do Brasil, juntamente com o SEBRAE, Governo do Estado e Prefeitura Municipal, implantou a Estratégia DRS (Desenvolvimento Regional Sustentável) na COOBAN, com o objetivo de desenvolver uma atividade sustentável e economicamente viável na comunidade.

Hoje as 27 (vinte e sete) bordadeiras de Alagoa Nova passam por várias oficinas de capacitação, com o objetivo de aprimorar o produto para ampliar sua inserção no mercado, e possuem uma linha diversificada de produtos. Norteadas pelos princípios de solidariedade e inclusão social, elas reforçam os valores que as concebem como artesãs, empreendedoras, mulheres, esposas, mães, filhas e, sobretudo, cidadãs.

\section{ANÁLISE DOS RESULTADOS DA PESQUISA}

\subsection{Variável - Renda}

O aumento da renda é uma das variáveis de maior significado ao se pensar em desenvolvimento sustentável regional, tendo em vista que a variação desta gera condições de maior ou menor acesso a alimentação básica e outros aspectos como disponibilidade de moradia, água, saneamento básico, concentração de habitantes por domicílio, entre outros. Os dados obtidos na presente pesquisa apontam uma elevação da renda de $100 \%$ dos participantes, após a implantação da estratégia DRS (Desenvolvimento Regional Sustentável) do Banco do Brasil. Este resultado é atribuído ao apoio ao financiamento de pagamento facilitado e ao aumento das vendas dos produtos, resultado das atividades paralelas as de desenvol- vimento econômico, como a capacitação para a gestão do próprio negócio, obtida através de alianças estratégicas realizadas com empresas como SEBRAE. A média 5,0 obtida nos dois indicadores que formam a variável renda é considerada excelente dentro da escala trabalhada na pesquisa.

\subsection{Variável - Promoção/Divulgação}

Apesar da grande vocação e habilidade dos participantes de cooperativas, são visíveis as suas deficiências no que diz respeito a relações com o mercado. Nesse sentido, buscou-se identificar junto às artesãs da COOBAN, a avaliação das mesmas no que diz respeito a variável Promoção/Divulgação dos produtos a partir implementação da estratégia DRS na COOBAN. Como o articulador o Banco do Brasil se propõe a trabalhar toda a cadeia de valor desde o produtor até o consumidor, através de parcerias com órgãos públicos e privados, sendo assim espera-se que a percepção das artesãs da COOBAN no que diz respeito à realidade mercadológica tenha sido ampliada.Para identificar o comportamento da variável promoção/divulgação, utilizou-se três indicadores, sendo o primeiro Maior Divulgação do Trabalho, apresentando média 4, 9, considerada muito satisfatório, o que indica o sucesso do trabalho realizado pelos parceiros no sentido de detectar o público-alvo do produto produzido e comercializado pela COOBAN e a partir desta ação de mercado, utilizar os melhores canais de comunicação, elevando consideravelmente a visibilidade dos produtos junto ao seu público-alvo. O segundo indicador trabalhando foi o Aumento ao Acesso a Feiras de Artesanato, tendo apresentado uma ponderação de 5,0 , ou seja, alcançando o ápice da escala trabalhada no instrumento de pesquisa, tal resultado aponta a participação efetiva e sistemática das artesãs em feiras de artesanato de todo o país. O ultimo indicador trabalhado nesta variável foi o Pretensão de Exportar os Produtos, este obteve média 4, 9, também considerada muito satisfatória. Sendo assim a variável Promoção/ Divulgação obteve média geral de 4,9 considerada satisfatória, tendo em vista que apenas dois dos indicadores trabalhados na referida variável não apresentaram a média máxima mas se aproximaram muito 
do resultado considerado excelente, o que nos leva a entender que as alianças firmadas através da estratégia DRS/BB estão favorecendo o maior acesso às informações sobre o mercado, uma condição de integração com outros artesãos e clientes através da participação periódica em feiras de artesanato em nível nacional, o que gerou uma compreensão do valor do seu produto e o entendimento de que o mesmo é demandado inclusive por clientes de outros países, Diante dos resultados apresentados nesta variável pode-se afirmar que os canais de comunicação utilizados atualmente como Site do Governo do Estado e a participação em feiras de artesanato em âmbito nacional, tem levado a maior visibilidade dos produtos da COOBAN junto aos clientes reais e potenciais.

Vale salientar que esta percepção positiva do ambiente externo levou as artesãs a adquirir maior confiança nos produtos que produzem, passando agora a preocupar-se em trabalhar a qualidade destes, para que os mesmos sejam inseridos nos padrões de competitividade internacional.

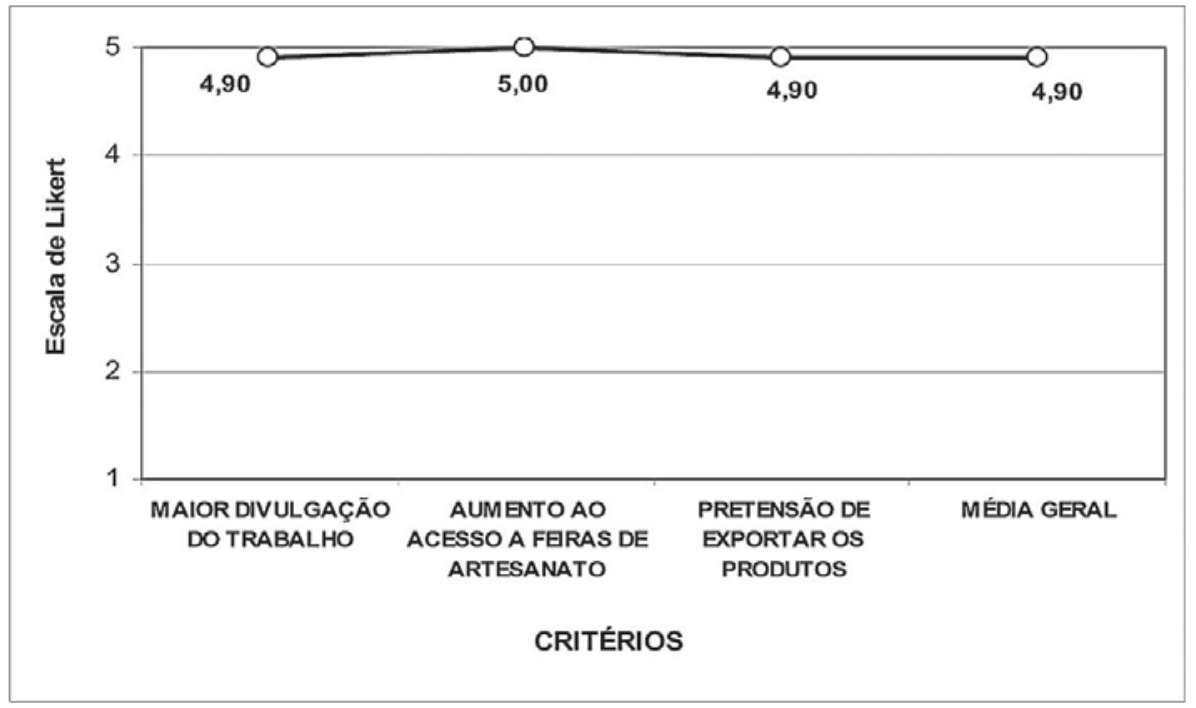

Gráfico 1. Médias dos critérios utilizados na variável promoção/divulgação, Alagoa Nova, PB.

Fonte: Pesquisa direta, 2006.

\subsection{Variável - Acesso ao Crédito}

Historicamente o acesso ao crédito bancário foi um dificultador para o crescimento dos pequenos empreendedores, com a inclusão da COOBAN no programa de DRS/BB todas as artesãs tiveram acesso a cartão de crédito e a linhas de financiamentos exclusivas, inclusive o PRONAF Mulher, pois além de artesãs, a maioria trabalha na agricultura, também puderam abrir contas bancárias, o que impacta diretamente na possibilidade de investimento no próprio negócio e na melhoria da qualidade de vida destas pessoas. Sendo assim, ao se trabalhar a variável Acesso ao Crédito buscou-se idenficar, na percepção das artesãs, o quanto esta estava influenciando positivamente o crescimento da COOBAN. Para tanto utilizou-se dois indicadores, o primeiro Maior Acesso ao Crédito, que buscou identificar se realmente elas agora tinham mais ingresso as linhas de créditos e se estas eram capazes de elevar os níveis dos produtos da COOBAN, este indicador apresentou a média 4,5 considerada satisfatória, o que implica que as artesãs já possuem maior crédito, o que, sem sombra de dúvidas, é um implicador positivo para a melhoria dos produtos desenvolvidos pelas mesmas. Quanto ao segundo indicador, Preciso para Manter o Negócio, obteve-se a média de 3,1, o que nos leva a concluir que é necessária uma maior ênfase na capacitação gerencial destes participantes do programa, em especial, no que diz respeito a administração 
financeira, pois mesmo que tenham mais acesso ao crédito se ainda não conseguem identificar o quanto ou o que precisam para manter o negócio pode alocar recursos de forma inadequada, o que minizará a probabilidade de tornarem-se auto-sustentáveis.
A média geral da Variável Acesso ao Crédito foi 3,8 considerada como relativamente satisfatória, o que nos leva a indicar a necessidade de maiores investimentos nas ações estratégicas que envolvem essa variável.

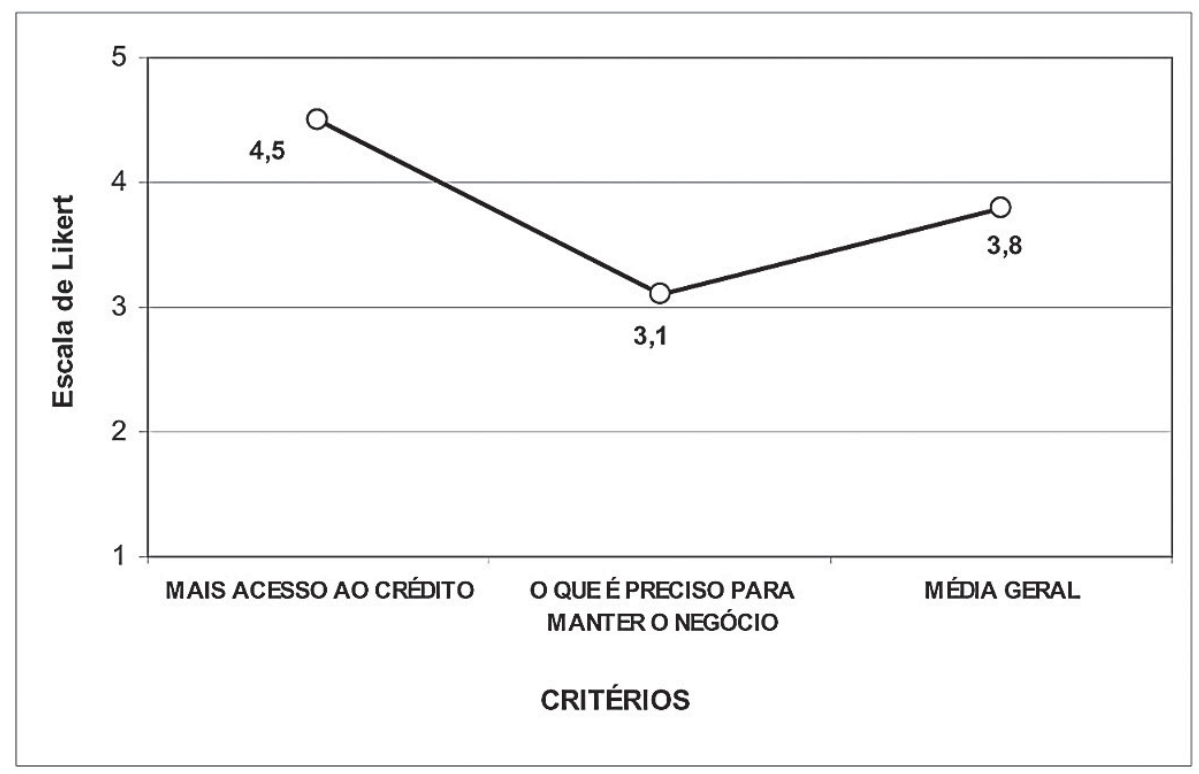

Gráfico 2. Médias dos critérios utilizados na variável acesso ao crédito, Alagoa Nova, PB. Fonte: Pesquisa direta, 2006.

\subsection{Variável - Auto-Estima}

O Programa DRS/BB é estruturado no tripé "economicamente viável, socialmente justo e ecologicamente correto", sendo assim, estimular o desenvolvimento sustentável detectando vocações regionais e valorizando o potencial local, requer antes de tudo ações integradas que elevem a auto-estima das cooperadas para que as mesmas possam adotar uma postura adequada ao bom andamento dos negócios. A baixa auto-estima limita a possibilidade de uma vida harmoniosa seja em termos pessoais ou profissionais.

Sendo assim, trabalhou-se a Variável AutoEstima com a intenção de identificar se esta foi ou não atingida a partir das ações integradas do Programa DRS/BB. Para tanto utilizou-se quatro indicadores, o primeiro Orgulho do Trabalho que Faço, apresentou uma média 5,0, considerada excelente, o que implica em um fator extremamente positivo, tendo em vista que orgulhar-se do que faz está diretamente ligado a escolher o que fazer, ou seja, ter vocação para tal. O segundo indicador trabalhado foi o "Condições de Ajudar a Família”, este apresentou média 4,8 considerada muito satisfatória, mostrando que se sentem úteis, fato este primordial para a elevação da autoestima de qualquer indivíduo.

O terceiro indicador, Crescimento do Trabalho enquanto Cooperativa, apresentou uma média 5,0 , considerada excelente, e constatou que na percepção das artesãs quanto às possibilidades de aumento na produção e na qualidade dos produtos desenvolvidos através do cooperativismo é fator fundamental para o êxito do empreendimento. O quarto e ultimo indicador trabalhado nesta variável foi, Melhores Condições de Saúde, Lazer e Educação, apresentando um decréscimo de 0,6 pontos e média de 4,4, considerada razoávelmente satisfatória, o que representa uma dificuldade com das artesãs com relação à gestão dos recursos financeiros, que por 
ter tido acréscimo, como foi apontando na variável renda, deveria está sendo refletido em melhores condições de saúde, educação e lazer para as próprias artesãs e suas famílias.

Analisando dentro de um contexto geral a média da variável auto-estima foi de 4,8 considerada muito satisfatória o que reflete uma melhoria considerável na auto-estima destas artesãs o que favorece o maior engajamento nos processos da COOBAN e o impacto positivo na estratégia DRS/ BB.

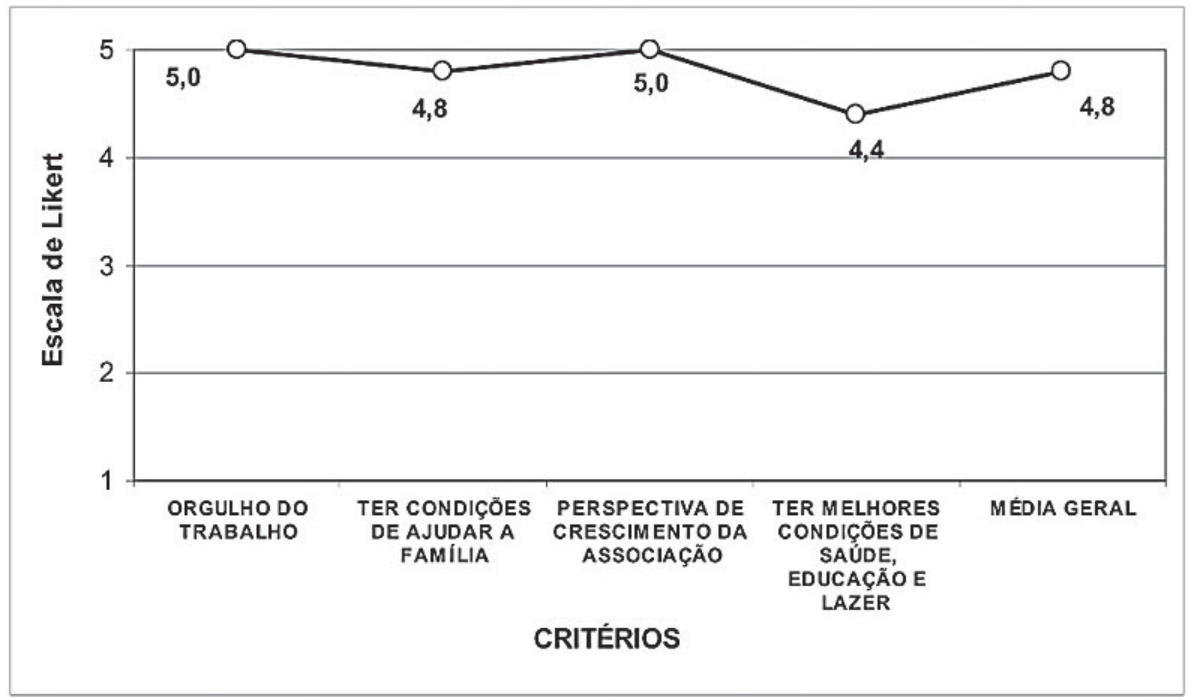

Gráfico 3. Médias dos critérios utilizados na variável auto-estima, Alagoa Nova, PB. Fonte: Pesquisa direta, 2006.

\subsection{Variável - Sustentabilidade}

A variável sustentabilidade, considerada essencial aos objetivos desta pesquisa, foi trabalhada através dos indicadores Segurança em Administrar o Próprio Negócio e Consciência da Existência de Demanda, adotou-se estes indicadores por considerar que o retorno financeiro é determinante da sustentabilidade de qualquer projeto, e para que o mesmo ocorra, os cooperados devem estar preparados para fazer com que a COOBAN funcione indefinidamente mesmo após o fim da assistência externa oferecida a partir da DRS/BB. O primeiro indicador, que avaliou a segurança na administrar o negócio, apresentou média 3, 9, considerada pouco satisfatória, indicando necessidade de intervenção dos parceiros no que diz respeito a trabalhar a autonomia e a autoconfiança das artesãs no que diz respeito à gestão da cooperativa. O segundo indicador, referente à consciência da demanda existente ou a ser explorada, apresentou média 4,9, considerada muito satisfatória pela proximidade da concordância total $\mathrm{O}$ que nos faz concluir que o trabalho feito pelos parceiros da DRS/BB surtiu um efeito positivo no que diz respeito à ampliação da visão sobre oportunidades de mercado, fato que eleva substancialmente a possibilidade de conseguirem o retorno necessário para tornarem a COOBAN autosustentável.

Sendo assim, a análise geral da variável sustentabilidade obteve média 4,4, considerada razoavelmente satisfatória, ou seja, refletindo a necessidade de uma atenção maior por parte dos responsáveis pela aliança estratégica, principalmente no que diz respeito à média 3,9 apontada pelo indicador, Segurança em Administrar o Negócio, para que essa não gere uma dependência nas artesãs, dificultando à continuidade das ações e a adaptação à realidade de mercado, atributo essencial a sustentabilidade. 


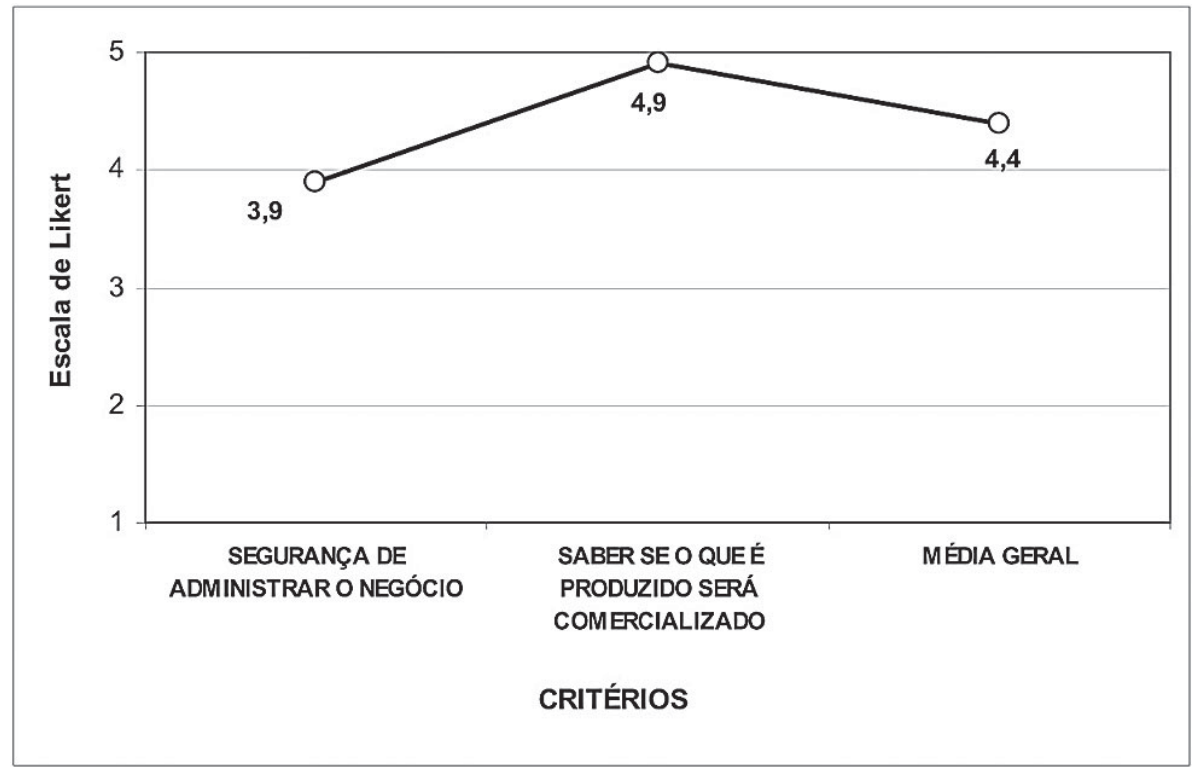

Gráfico 4. Médias dos critérios utilizados na variável sustentabilidade, Alagoa Nova, PB. Fonte: Pesquisa direta, 2006.

\section{6 análise geral das variáveis}

A avaliação geral das variáveis da pesquisa obteve média geral de 4,6, considerada satisfatória, tendo em vista que o ápice da escala trabalhada é a média 5,0, considerada excelente e a diferença apontada entre esta e a média geral é de apenas 0,4 pontos. Vale salientar que entre as cinco variáveis trabalhadas a, Renda, foi a única que apresentou a média máxima, 5,0, seguida pela Promoção e Divulgação com média 4,9, considerada muito satisfatória, e pela variável Auto-Estima, com média 4,8, também revelando um resultado muito próximo do considerado ideal. As variáveis que apresentaram resultados razoáveis foram a Sustentabilidade, com média 4,4 tendo como principal motivo identificado a inse-

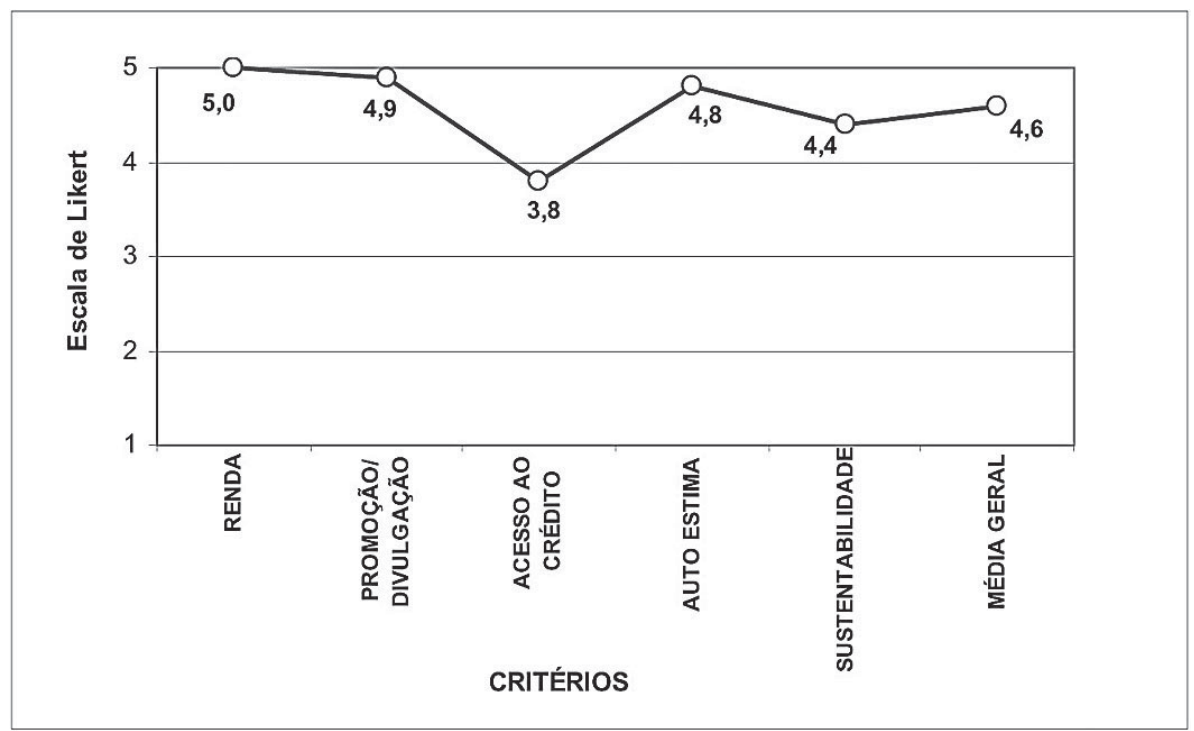

Gráfico 5. Média geral das variáveis trabalhadas, Alagoa Nova, PB.

Fonte: Pesquisa direta, 2006. 
gurança das artesãs no que diz respeito a administrar a cooperativa, e a que apresentou a média que mais se distanciou da ideal foi a variável Acesso ao crédito, com média 3,8, o que pode ser explicado pelo fato das artesãs ainda não estarem conscientes de quanto precisam pra que seu negócio funcione plenamente e por ainda não ter sido liberada, apesar de aprovada, a verba que a Fundação Banco do Brasil irá destinar a COOBAN.

\section{CONSIDERAÇÕES FINAIS}

O modelo organizacional de bases cooperativistas, com instâncias colegiadas e decisões de ganhos segundo a produção, revelou-se bastante eficaz no que diz respeito à superação dos obstáculos gerados pelo processo de globalização e suas conseqüências no mundo do trabalho. No caso da COOBAN, têm-se indivíduos de baixa renda e escolaridade, que dispõem de vocação para o artesanato. Sendo assim, para que possam colocar em prática suas habilidades e ao mesmo tempo obterem condições dignas de vida, se faz necessário um apoio externo, para alavancar o projeto, através do acesso facilitado ao crédito e de capacitações na área de gestão.

Neste contexto, este trabalho buscou analisar o impacto da implementação da estratégia de Desenvolvimento Regional Sustentável - DRS do Banco do Brasil na COOBAN - Cooperativa das Bordadeiras de Alagoa Nova. Para tanto trabalhouse as variáveis: Renda; Promoção/Divulgação; Acesso ao Crédito; Auto-Estima e Sustentabilidade, tendo como base o arcabouço teórico relacionado ao tema em questão, chegou-se a seguinte conclusão:

A variável Renda apresentou o impacto mais positivo, resultado obtido através do aumento nas vendas e encomendas dos produtos produzidos pelas artesãs da COOBAN. Sendo assim, foi comprovado que o rateio, entre as cooperadas, dos exercícios financeiros, após a implementação da estratégia DRS$\mathrm{BB}$, mostrou-se superior aos anteriores.

A variável Promoção/Divulgação, resultou impacto muito positivo, em virtude da participação periódica em feiras de artesanato em nível nacional e a participação da COOBAN no site do Governo do Estado. Vale destacar o fato de que as artesãs despertaram para a possibilidade de alcançar o mercado externo, o que demanda uma atenção maior na qualidade e quantidade dos produtos desenvolvidos pela cooperativa.

Quanto ao Acesso ao Crédito sua performance foi bem abaixo do esperado, o que tem demonstrado insegurança por parte das artesãs no que diz respeito ao entendimento dos custos financeiros relacionados à manutenção da cooperativa.

Por outro lado, a Auto-Estima mostrou um impacto positivo, mas no entanto, revela a mesma deficiência das cooperadas em administrar questões financeiras, já que apesar de afirmarem ter melhores condições de ajudar seus familiares, revelam uma falta de planejamento ao apresentarem média baixa quanto ao investimento em educação, saúde e lazer.

A Sustentabilidade, apresentou performance abaixo média considerada ideal, devido à falta de segurança exposta pelas próprias artesãs, no que diz respeito à administração da cooperativa após a saída do apoio externo. Destaca-se no entanto o maior conhecimento, por parte das mesmas, das demandas a serem supridas ou ainda exploradas.

A possibilidade da COOBAN gerar ainda mais emprego e renda foi constatada neste estudo, o que implica dizer que o trabalho articulado pelo Banco do Brasil a partir da estratégia DRS, vem impactando positivamente a Cooperativa. No entanto é preciso destacar pontos que se apresentaram como passiveis de melhorias para que os mesmos não prejudiquem o resultado esperado tanto pelos cooperados quanto pelos responsáveis pela aliança estratégica, que é contribuir para o desenvolvimento sustentável daquela região.

As variáveis que apresentaram médias gerais abaixo das consideradas ideais ou próximas da situação adequada, foram Acesso ao Crédito e Sustentabilidade com 4,4, os indicadores responsáveis 
pela queda da média geral, referem-se à falta de segurança das artesãs em gerenciarem a cooperativa e auto gerenciarem financeiramente sendo importante o desenvolvimento de medidas corretivas como: a capacitação na área financeira e de gestão de negócios, ampliação dos canais de distribuição, tendo em vista que está sendo estimulada a demanda e o contínuo monitoramento do processo pelos próprios cooperados em parceria com os responsáveis pela DRS-BB.

Sendo assim, conclui-se que os impactos da implementação da estratégia DRS do Banco do Brasil junto a Cooperativa das Bordadeiras de Alagoa Nova - COOBAN tem se mostrado positivo, no entanto vale ressaltar que os pontos passíveis de melhorias detectados nesta pesquisa precisam ser trabalhados de forma estratégica a fim de gerar a autonomia destes cooperados.

\section{REFERÊNCIAS}

BARBIERI, José Carlos. Desenvolvimento e meio ambiente: As Estratégias de Mudanças da Agenda 21. Rio de Janeiro: Vozes, 2000.

BARONI, Margaret. Ambigüidade e deficiências do conceito de desenvolvimento sustentável. In: Revista de Administração de Empresas. São Paulo, 32. abr./jun. 1992. p. 14-24.

BRUSEK, Fraz Josef. O problema do desenvolvimento sustentável. In: CAVALCANTI, Clóvis (Org.). Desenvolvimento e Natureza: Estudo para uma Sociedade Sustentável. São Paulo; Cortez: Recife: Fundação Joaquim Nabuco, 1995.

CAVALCANTI, Clóvis (Org.). Meio ambiente, desenvolvimento sustentável e políticas públicas. São Paulo: Cortez; Recife: Fundação Joaquim Nabuco, 1997.

EHLERS, Eduardo. Agricultura sustentável: origens e perspectivas de um novo paradigma. São Paulo: Livros da Terra, 1996.

\section{GIL, Antonio C. Como elaborar projetos de pes-}

quisa. 3. ed. São Paulo: Atlas, 1999.

GUEMAWAT, P. A estratégia e o cenário de negócios: textos e casos. Porto Alegre: Bookman, 2000.

JARA, Carlos Julio. A sustentabilidade do desenvolvimento local. Instituto Interamenricano de Cooperativa para a Agricultura (IICA), Recife Secretaria de Planejamento do Estado de Pernambuco - Seplan, 1998.

KEEGAN, W. J. e GREen, M. C. Princípios de marketing global. São Paulo: Saraiva, 1999.

LAROUSSE, Koogan. Pequeno dicionário enciclopédico. Rio de Janeiro: Ed. Larousse do Brasil, 1980.

LIVRO DE INSTRUÇÕES CODIFICADAS - LIC. Banco do Brasil, 2006.

LORANGE, P. Alianças estratégicas: formação, implementação e evolução. São Paulo: Atlas, 1996.

MAIA, Lindalva Silva Correia. Desenvolvimento sustentável e a sua aplicabilidade nas políticas públicas do nordeste nos anos 20. Monografia apresentada ao Curso de Economia. Universidade Federal da Paraíba, Campus II. Campina Grande, 2000.

MINTZBERG, H; QUINN, J. O processo de estratégia. Porto Alegre: Bookman, 2001.

MUGGIATI, André. Conhecimento e curiosidades à velocidade da luz - RIO $+10=0$. Revista Super Interessante. Sessão: Super Novas. São Paulo, SP. Editora Abril. Edição 181, out., 2002.

OLIVEIRA, Djalma de P. R. Excelência na administração estratégica: a competitividade para administrar o futuro das empresas: com depoimentos de executivos. 3. ed. São Paulo: Atlas, 1997.

PINHEIRO, Paulo Sérgio. Brasil: um século de transformações. São Paulo: Companhia das Letras, 2001. 
RUDIO, Franz Victor. Fundamentos da metodologia científica. São Paulo: Atlas, 2003.

SAMARA, Beatriz Santos e BARROS, José Carlos de. Pesquisa de marketing - conceitos e metodologia. São Paulo: Prentice-Hall, 2001.

SCHETTINO, Luiz Fernando; BRAGA, Geraldo Magela. Agricultura familiar e sustentabilidade. Vitória, ES: Ed. Do Autor, 2000.

THOMPSON JR, A. e STRICKLAND III, A. Planejamento estratégico: elaboração, implementação e execução. São Paulo: Pioneira, 2000.

TRIVIÑOS, Augusto Nibaldo Silva. Metodologia da pesquisa em ciências sociais. São Paulo: Atlas, 1990.

VEIGA, J. E. da. Problemas da transição à agricultura sustentável. Estudos Econômicos. São Paulo, v. 24, no especial, p. 9-29, 1994.

YOSHINO, M. Y. e RANGAN, S. V. Alianças estratégicas: uma abordagem empresarial à globalização. São Paulo: Editora Makron Books, 1996. 